\title{
Evaluating the assumptions of surface reflectance and aerosol type selection within the MODIS aerosol retrieval over land: the problem of dust type selection
}

\author{
T. Mielonen ${ }^{1}$, R. C. Levy ${ }^{2,3}$, V. Aaltonen ${ }^{4}$, M. Komppula ${ }^{1}$, G. de Leeuw ${ }^{4,5,6}$, J. Huttunen ${ }^{1}$, H. Lihavainen ${ }^{4}$, \\ P. Kolmonen ${ }^{4}$, K. E. J. Lehtinen ${ }^{1,7}$, and A. Arola ${ }^{1}$ \\ ${ }^{1}$ Finnish Meteorological Institute, Kuopio Unit, Kuopio, Finland \\ ${ }^{2}$ Science Systems and Applications Inc., Lanham, MD, USA \\ ${ }^{3}$ NASA/Goddard Space Flight Center, Greenbelt, MD, USA \\ ${ }^{4}$ Finnish Meteorological Institute, Climate Change, Helsinki, Finland \\ ${ }^{5}$ Department of Physics, University of Helsinki, Helsinki, Finland \\ ${ }^{6}$ TNO Built Environment and Geosciences, Utrecht, The Netherlands \\ ${ }^{7}$ Department of Applied Physics, University of Eastern Finland, Kuopio, Finland
}

Received: 30 July 2010 - Published in Atmos. Meas. Tech. Discuss.: 17 August 2010

Revised: 10 January 2011 - Accepted: 23 January 2011 - Published: 9 February 2011

\begin{abstract}
Aerosol Optical Depth (AOD) and Ångström exponent (AE) values derived with the MODIS retrieval algorithm over land (Collection 5) are compared with ground based sun photometer measurements at eleven sites spanning the globe. Although, in general, total AOD compares well at these sites $\left(R^{2}\right.$ values generally over 0.8$)$, there are cases (from 2 to $67 \%$ of the measurements depending on the site) where MODIS clearly retrieves the wrong spectral dependence, and hence, an unrealistic AE value. Some of these poor $\mathrm{AE}$ retrievals are due to the aerosol signal being too small (total AOD $<0.3$ ) but in other cases the AOD should have been high enough to derive accurate AE. However, in these cases, MODIS indicates AE values close to 0.6 and zero fine model weighting (FMW), i.e. dust model provides the best fitting to the MODIS observed reflectance. Yet, according to evidence from the collocated sun photometer measurements and backtrajectory analyses, there should be no dust present. This indicates that the assumptions about aerosol model and surface properties made by the MODIS algorithm may have been incorrect. Here we focus on problems related to parameterization of the land-surface optical properties in the algorithm, in particular the relationship between the surface reflectance at 660 and $2130 \mathrm{~nm}$. The retrieval assumes that there is a linear equation that relates the reflectance in these two channels, with the value of the slope
\end{abstract}

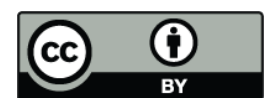

Correspondence to: T. Mielonen (tero.mielonen@fmi.fi) (slope $660 / 2130$ ) determined, in part, by the infrared Normalized Difference Vegetation Index, (NDVI SwIR $_{\text {). However, }}$ the assumed dependence of the slope on the NDVI SwIR $_{\text {is }}$ not supported by a MODIS based surface albedo climatology. The use of a modified relationship based on the albedo data improves the AE retrieval at the studied sites. The increase in the AE agreement fraction between MODIS and AERONET measurements is between 3 and 22 percentage units depending on the site. These results indicate that the surface reflectance assumptions, especially the slope $660 / 2130$ in the MODIS algorithm is the major reason for the inaccurate $\mathrm{AE}$ values and the flawed aerosol model combining in the retrieval. However, at some of these sites, the new relationship slightly reduces the correlation between the MODIS and AERONET AOD. This decrease indicates that the combination of the assumed surface and aerosol properties still do not match the actual properties under investigation.

\section{Introduction}

Aerosols play an important role in the Earth's atmosphere. They affect, for example, climate, radiation budget and cloud processes. The direct effect of aerosols on climate involves both scattering and absorption of radiation, while the indirect effect of aerosols is related to their ability to modify the optical and physical properties and thus also the lifetimes of clouds. Aerosols are ubiquitous and therefore satellite

Published by Copernicus Publications on behalf of the European Geosciences Union. 
measurements can provide global aerosol information. However, because of the huge variety of aerosol and surface conditions, passive satellite algorithms are underdetermined in their information content. Therefore, to retrieve realistic aerosol properties, the algorithms require reasonable assumptions and constraints on aerosol properties and the contributions of the underlying surface to the observed radiance field. The quality of the assumptions is critical, especially over land where the surface reflectance can dominate the reflectance measured at the top of the atmosphere. Due to the stronger signal from the surface, the error in the derived aerosol optical depth (AOD) is typically 10 times larger than the error in the retrieved surface reflectance (Kaufman et al., 1997). Consequently, developing satellite retrieval algorithms is hard.

One of the most widely used passive satellite instruments in aerosol remote sensing is the Moderate Resolution Imaging Spectroradiometer (MODIS, Salomonson et al., 1989). MODIS instruments are aboard the Terra and Aqua satellites. Having a swath width of $2300 \mathrm{~km}$, Terra MODIS and Aqua MODIS cover the Earth's surface every 1 to 2 days. Beginning in early 2007, a consistent algorithm (Levy et al., 2007a) was used to process the entire MODIS data record, providing the so-called Collection 5 (hereafter C5) data set. Levy et al. (2007a, and the on-line ATBD) have provided a detailed documentation of the algorithm and the changes from previous versions.

The C5 over land algorithm differs from prior versions in its retrieval process logic, as well as in its assumptions about aerosol model optical properties and surface reflectance. The algorithm makes a simultaneous inversion of MODIS-observed reflectance in three channels $(0.47,0.66$ and $2.13 \mu \mathrm{m}$ ), to retrieve total aerosol loading, proportion of fine/coarse aerosol particles, and surface reflectance. The products are three semi-independent parameters, the total AOD (or $\tau$ ) at $0.55 \mu \mathrm{m}$, the nondust or fine model weighting (FMW), and the surface reflectance at $2.13 \mu \mathrm{m}$. FMW is the fractional contribution of fine mode aerosol to the total $\mathrm{AOD}$ at $0.55 \mu \mathrm{m}$.

C5 uses five aerosol models (Levy et al., 2007b), four of which are used in the standard algorithm: dust, weakly absorbing, moderately absorbing and strongly absorbing. Each of these four models has been determined by analysis of AERONET almucantar inversions (e.g. Dubovik et al., 2002), and are comprised of two lognormal modes in their size distribution. The dust model is non-spherical and dominated by coarse mode, whereas the other three are spherical and dominated by the fine mode. The three fine models are different mainly in their single scattering albedo (SSA), such that the weakly, moderately and strongly absorbing models have approximate SSA at $550 \mathrm{~nm}$ of $0.95,0.91$ and 0.86 , respectively. The dust model has a SSA of 0.95 (Levy et al., 2010). The value of the FMW represents the "mixture" of one of the fine-dominated models (hereafter fine model) and the dust model, where the fine model is prescribed by geog- raphy and season. Thus, the FMW is not a weight between fine and coarse modes, but represents the proportion of nondust aerosol model. A FMW value of zero represents the case where the dust model provides the best solution. The retrieved spectral AOD represents the optical contributions of the dust/non-dust mixture, from which the Ångström exponent (AE) can be derived.

Validation with data from the Aerosol Robotic Network (AERONET, Holben et al., 1998) shows that retrieval of AOD has improved compared to C4 (Levy et al., 2007a; Mi et al., 2007; Papadimas et al., 2008; Jethva et al., 2007). Moreover, MODIS C5 measurements have been extensively compared with AERONET measurements globally (Levy et al., 2010; Levy et al., 2007a; Jethva et al., 2010; Jethva et al., 2007; Mi et al., 2007; Kaskaoutis et al., 2007; Papadimas et al., 2008; Misra et al, 2008; Drury et al., 2008; Remer et al., 2008, Mishchenko et al., 2010). Several studies, for example Jethva et al. (2010) and Oo et al. (2008) have concluded that the surface assumptions and aerosol models in the MODIS retrieval are not representative for all locations. As for AE, there have been no comprehensive studies comparing MODIS and AERONET values of AE. Levy et al. (2007a) did not find high levels of correlation from their small sample of comparisons. Mishchenko et al. (2007), Liu and Mishchenko (2008) and Mishchenko et al. (2009) compared MODIS to retrievals from the Multi-angle Imaging SpectroRadiometer (MISR, Kahn et al., 2001) and found no correlation between the two instruments, further indicating that the information observed by passive satellite techniques over land is weak. Although Kahn et al. (2009) showed that some of the poor comparisons were resulting from data misinterpretation, retrieval of global AE is still considered a difficult problem.

Why are the AE discrepancies so large, even when total AOD is comparable? Why does MODIS retrieval report $100 \%$ dust, even in regions, where no significant dust loading should be expected? This study addresses the question why the MODIS algorithm wrongly selects the dust model in such cases. Previous studies have suggested, and Levy et al. (2010) have stated, that the MODIS observations do not contain enough information to robustly separate dust from non-dust. Uncertainties in the surface reflectance, as well as in aerosol absorption are too large. However, from the collocations with sun photometer data, we can begin to quantitatively evaluate these systematic errors. In some sites the misidentification occurs because the surface reflectance assumptions are consistently wrong, whereas at other sites, the error is dominated by the initial assumption of aerosol model type. In this paper, we study some of the sites where MODIS is consistently picking the wrong aerosol model, which in turn leads to errors in total AOD and especially in AE. We determine the dominant cause of aerosol type mis-identification, and determine whether the retrieval can be tuned in a physically meaningful way at these sites. 
Table 1. Sunphotometer sites used in the study. PFR sites were in Finland and AERONET data was used elsewhere.

\begin{tabular}{lllr}
\hline Site & Country & Lat., Lon. & Elevation $[\mathrm{m}]$ \\
\hline PFR: & & & \\
Jokioinen & Finland & $60.81^{\circ} \mathrm{N}, 23.50^{\circ} \mathrm{E}$ & 104 \\
Sodankylä & Finland & $67.37^{\circ} \mathrm{N}, 26.63^{\circ} \mathrm{E}$ & 184 \\
AERONET: & & & \\
Alta Floresta & Brazil & $9.87^{\circ} \mathrm{S}, 56.10^{\circ} \mathrm{W}$ & 277 \\
GSFC & USA & $38.99^{\circ} \mathrm{N}, 76.84^{\circ} \mathrm{W}$ & 87 \\
Ispra & Italy & $45.80^{\circ} \mathrm{N}, 8.63^{\circ} \mathrm{E}$ & 235 \\
Kanpur & India & $26.51^{\circ} \mathrm{N}, 80.23^{\circ} \mathrm{E}$ & 123 \\
Mexico City & Mexico & $19.33^{\circ} \mathrm{N}, 99.18^{\circ} \mathrm{W}$ & 2268 \\
Mongu & Zambia & $15.25^{\circ} \mathrm{S}, 23.15^{\circ} \mathrm{E}$ & 1107 \\
Rome Tor Vergata & Italy & $41.84^{\circ} \mathrm{N}, 12.65^{\circ} \mathrm{E}$ & 130 \\
Tóravere & Estonia & $58.26^{\circ} \mathrm{N}, 26.46^{\circ} \mathrm{E}$ & 70 \\
Xianghe & China & $39.75^{\circ} \mathrm{N}, 116.96^{\circ} \mathrm{E}$ & 36 \\
\hline
\end{tabular}

\section{Data and methodology}

In this study, AOD available from MODIS is compared with AOD measured with ground-based Precision Filter Radiometers (PFR, Kim et al., 2008) located in Finland. In addition, MODIS measurements are compared with Aerosol Robotic Network (AERONET, Holben et al., 1998) Cimel sun photometer measurements. The sites are listed in Table 1. PFR measurements in Sodankylä and Jokioinen were made between 2004 and 2008, and 2006 and 2008, respectively. For both sites, data from days with residual snow on the ground were removed from the analysis because snow would render the MODIS retrieval difficult. Cimel measurements at the AERONET sites were done between 2000 and 2008.

\subsection{MODIS data}

MODIS C5 data from both satellites are used in the comparisons with the ground-based measurements. The expected error over land in the MODIS AOD (or $\tau$ ) is $\pm 0.05 \pm 0.15 \tau$ (Levy et al., 2010). We used level 2 AOD data which has a spatial resolution of $10 \times 10 \mathrm{~km}^{2}$ at nadir. Only AOD data with best quality (Quality flag $=3$ ) were considered in the analysis (Levy et al., 2010). For the comparisons with sun photometer measurements we used Optical_Depth_Land_And_Ocean product. In the more detailed analysis of the MODIS retrieval algorithm we used Corrected_Optical_Depth_Land product. These data were downloaded from LAADS Web (http://ladsweb.nascom.nasa.gov/ data/search.html).

\subsection{Sun photometer data}

Two different types of sun photometer instruments were used in this study. The Precision Filter Radiometer (PFR; Wehrli, 2000; Kim et al., 2008) is a passive instrument which measures direct solar irradiance in four narrow spectral bands
$(368,412,500$, and $862 \mathrm{~nm})$. The bandwidth of the instrument is $5 \mathrm{~nm}$ and the full field of view angle is 2.5 degrees. Derived products from the measurements are AOD for the four wavelengths and AE. The time resolution of the products is $1 \mathrm{~min}$. The absolute uncertainty in AOD of the PFR instrument is between 0.01 and 0.02 (Carlund et al., 2003). For the comparison with MODIS, the AOD measured by the PFR at $500 \mathrm{~nm}$ was interpolated to $550 \mathrm{~nm}$ using the Ångström power law, $\tau_{550}=\tau_{500}(550 / 500)^{-\alpha}$, where $\tau_{550}$ is the AOD at $550 \mathrm{~nm}, \tau_{500}$ is the AOD at $500 \mathrm{~nm}$ and $\alpha$ is the AE based on the linear fit taken over all four PFR wavelengths. Cloud screening of the PFR measurements is based on the method presented by Smirnov et al. (2000).

The Aerosol Robotic Network (AERONET; Holben et al., 1998) uses Cimel sun photometers which measure AOD at 340, 380, 440, 500, 675, 870 and $1020 \mathrm{~nm}$. Measurements are provided every $15 \mathrm{~min}$ during daytime. AERONET also provides the angular distribution of sky radiances at four wavelengths (440, 670, 870 and $1020 \mathrm{~nm})$, and aerosol properties such as aerosol size distribution, complex refractive index, and single scattering albedo (SSA), once every hour in clear sky conditions. The direct-sun AOD from AERONET are accurate to within \pm 0.01 for wavelengths larger than $400 \mathrm{~nm}$ and \pm 0.02 for shorter wavelengths (Holben et al., 1998; Eck et al., 1999). Holben et al. (1998) have described AERONET measurements in more detail. For the comparison with MODIS, the AOD measured by AERONET at $500 \mathrm{~nm}$ was interpolated to $550 \mathrm{~nm}$ by using the Ångström power law. We used cloud screened and quality assured level 2.0 data and level 2.0 inversion products in the analysis.

We compared the AERONET (Cimel) and PFR AOD measurements carried out at Sodankylä between March and September, 2007. For 1790 coexistent measurements with less than 3 minute time difference, the comparison showed that the ground based instruments agree extremely well at all comparable wavelengths. At visual and UV wavelengths 
Table 2. Statistics of the concurrent AERONET/PFR and MODIS AOD measurements. Subscript "all" refers to all coexistent measurements, "over" refers to measurements with MODIS AE over 1, and "under" refers to measurements with MODIS AE under $1 . n$ is the number of measurements, $R^{2}$ is the correlation coefficient, mean $(\mathrm{gb}-\mathrm{M})$ is the average difference between the ground-based and MODIS measurements, RMS diff is the Root-Mean-Square Difference, and Pixels is the percentage of pixels within the expected accuracy of MODIS. Coarse $_{\text {AERONET }}$ and Coarse MODIS are the percentages of coarse particle measurements at each site based on AERONET and MODIS data, respectively.

\begin{tabular}{|c|c|c|c|c|c|c|c|c|c|c|c|}
\hline & Alta Floresta & GSFC & Ispra & Jokioinen & Kanpur & Mexico City & Mongu & Rome & Sodankylä & Tõravere & Xianghe \\
\hline \multicolumn{12}{|l|}{ All measurements: } \\
\hline$n_{\text {all }}$ & 244 & 895 & 652 & 126 & 340 & 172 & 1085 & 785 & 127 & 252 & 462 \\
\hline$R_{\text {all }}^{2}$ & 0.97 & 0.93 & 0.90 & 0.90 & 0.80 & 0.64 & 0.87 & 0.78 & 0.80 & 0.95 & 0.94 \\
\hline mean $(\mathrm{gb}-\mathrm{M})_{\text {all }}$ & -0.02 & -0.02 & 0.02 & 0.01 & -0.06 & 0.01 & 0.01 & -0.02 & 0.02 & 0.02 & -0.02 \\
\hline RMS diff all & 0.20 & 0.05 & 0.06 & 0.03 & 0.14 & 0.10 & 0.08 & 0.05 & 0.03 & 0.05 & 0.12 \\
\hline Pixels [\%] & 67 & 92 & 86 & 97 & 79 & 71 & 85 & 88 & 92 & 87 & 80 \\
\hline Coarse $_{\text {AERONET }}[\%]$ & 14 & 4 & 6 & 10 & 49 & 12 & 4 & 12 & 0 & 8 & 30 \\
\hline Coarse $_{\text {MODIS }}[\%]$ & 21 & 40 & 2 & 37 & 92 & 67 & 21 & 70 & 17 & 16 & 84 \\
\hline \multicolumn{12}{|c|}{ Measurements with MODIS AE over 1: } \\
\hline$n_{\text {over }}$ & 193 & 541 & 640 & 79 & 26 & 56 & 862 & 233 & 105 & 212 & 76 \\
\hline$R_{\text {over }}^{2}$ & 0.97 & 0.96 & 0.90 & 0.90 & 0.82 & 0.68 & 0.89 & 0.77 & 0.81 & 0.96 & 0.96 \\
\hline mean $(\mathrm{gb}-\mathrm{M})_{\text {over }}$ & -0.03 & -0.02 & 0.02 & 0.01 & 0.07 & 0.03 & 0.02 & -0.00 & 0.02 & 0.02 & 0.02 \\
\hline RMS diff ${ }_{\text {over }}$ & 0.22 & 0.04 & 0.06 & 0.03 & 0.13 & 0.08 & 0.08 & 0.04 & 0.03 & 0.05 & 0.15 \\
\hline \multicolumn{12}{|c|}{ Measurements with MODIS AE under 1: } \\
\hline$n_{\text {under }}$ & 51 & 354 & 12 & 47 & 314 & 116 & 223 & 552 & 22 & 40 & 386 \\
\hline$R_{\mathrm{under}}^{2}$ & 0.64 & 0.67 & 0.72 & 0.89 & 0.82 & 0.62 & 0.56 & 0.77 & 0.80 & 0.90 & 0.93 \\
\hline mean $(\mathrm{gb}-\mathrm{M})_{\text {under }}$ & 0.05 & -0.03 & -0.00 & 0.01 & -0.07 & 0.01 & -0.01 & -0.02 & 0.02 & 0.00 & -0.03 \\
\hline RMS diff ${ }_{\text {under }}$ & 0.07 & 0.06 & 0.04 & 0.03 & 0.14 & 0.10 & 0.07 & 0.06 & 0.03 & 0.04 & 0.11 \\
\hline
\end{tabular}

$(368,412$ and $500 \mathrm{~nm})$ the correlation coefficients $\left(R^{2}\right)$ values were 0.99 . For the longer wavelength band $(862 \mathrm{~nm})$ the correlation is almost as good, with $R^{2}=0.97$. For the all the wavelengths the bias between the instruments was less than 0.01. This and previous analyses (e.g. Kim et al., 2008) show that PFR and AERONET measured AOD are of similar quality.

\subsection{Collocation of MODIS and sun photometer data}

The ground-based measurements were used in the analysis only if the measurements were made within an one hour window centered at the MODIS overpass. The averaging of the satellite and surface measurements was based on the method described by Ichoku et al. (2002). If MODIS had more than 5 aerosol retrievals inside a grid of $5 \times 5$ pixels $\left(50 \times 50 \mathrm{~km}^{2}\right)$, centered at an AERONET/PFR station, these retrievals were averaged and compared to ground-based measurements. In addition, ground-based measurements were used in the analysis only if there were more than 6 PFR or 3 AERONET measurements within the one hour window. This was done to ensure that one instrument did not measure in the beginning of the time window and the other one in the end.

Comprehensive global comparisons between AERONET and MODIS are presented by Levy et al. (2010), here we compare MODIS and sun photometer data for the specific sites, where there are many cases where MODIS is not identifying dust properly. Table 2 summarizes the differences be- tween MODIS and AERONET/PFR AOD measurements at the sites studied. All parameters are presented for all measurements, for the measurements with MODIS AE over 1, and for the measurements with MODIS AE under 1. The measurements were stratified by the MODIS AE in order to study how errors in AE are tied to errors in AOD. In addition, Table 2 includes the percentage of coarse particle measurements at each site based on AERONET and MODIS data (amount of measurements with AE under 1). The AERONET values show that in Kanpur $49 \%$ of the coexistent measurements has coarse aerosols while in Xianghe the fraction is $30 \%$. The other sites do not have significant amounts of coarse aerosols. However, AE data from MODIS suggests that the coarse fraction is larger than $15 \%$ at all the sites, except in Ispra where the fraction is only $2 \%$. In Kanpur the MODIS coarse fraction is as high as $92 \%$ while in Xianghe it is $84 \%$.

At Alta Floresta, GSFC, Ispra, Mexico City, Mongu, and Toravere the $R^{2}$ values are the lowest for the cases with $\mathrm{AE}$ under 1. At Jokioinen, Rome, Sodankylä, and Xianghe the values of $R^{2}$ for the measurements with $\mathrm{AE}$ under 1 are slightly lower or in the same range as in the other classes. At Kanpur the $R^{2}$ values are equal for the $\mathrm{AE}>1$ and $\mathrm{AE}<1$ classes. The averaged difference between the instruments (ground based - MODIS, henceforth mean $(\mathrm{gb}-\mathrm{M})$ ) and the Root-Mean-Square of the difference (RMS diff) are very similar for all categories. In addition, Table 2 shows the percentage of the measurements within the expected MODIS 

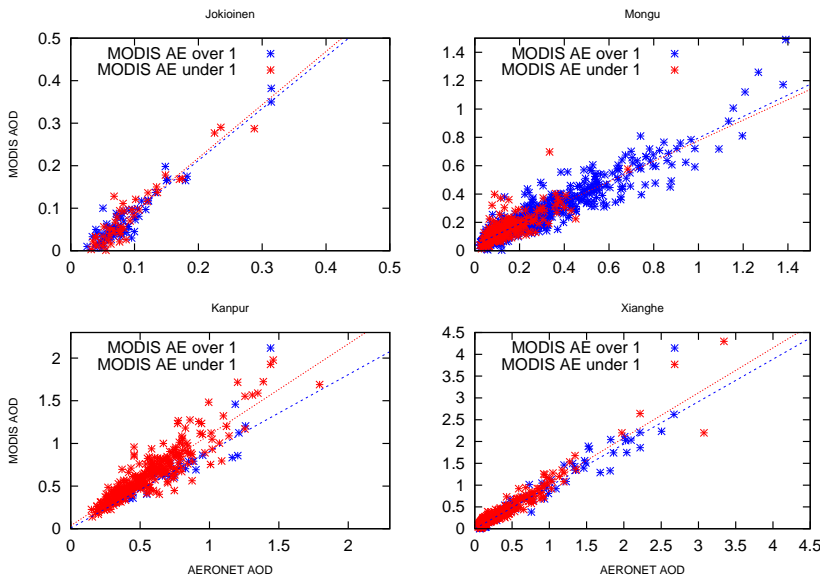

Fig. 1. Correlation of AERONET/PFR and MODIS measurements in Jokioinen, Mongu, Kanpur and Xianghe. Blue points indicate measurements with MODIS AE over 1, and red points measurements with MODIS AE smaller than 1. Statistics for the comparisons are shown in Table 1.

accuracy. At all sites the percentages are larger or in the same range as the results presented by Remer et al. (2008) and Jethva et al. (2007). Both reported that more than $70 \%$ of the measurements at $550 \mathrm{~nm}$ over land were within expected accuracy.

Figure 1 shows examples of comparisons of the AODs from MODIS and ground-based instruments at $550 \mathrm{~nm}$ wavelength stratified by MODIS AE. For some sites (e.g. Jokioinen, Mongu), dust is known to be rare (see Table 2). However, it is common at those sites that MODIS retrieves $\mathrm{AE}<1$. The question is why? We found that: (1) Retrievals with $\mathrm{AE}<1$ are connected with AOD $<0.5$. (2) MODIS retrieves $\mathrm{AE}<1$ at all studied sites, thus the flawed dust model selection is not confined to specific aerosol types or surface types. For the sites where also AERONET indicated the presence of coarse aerosol particles (e.g. Kanpur and Xianghe, Table 2) the MODIS AE is under 1 also for larger AOD values and the $R^{2}$ values for the two size classes (under and over 1) are equal or in the same range.

Figure 2 shows the same data as Figure 1 but stratified by AERONET AE. Evidently, the number of measurements with $\mathrm{AE}<1$ is significantly lower than with the MODIS data at all sites. In addition, most of the measurements with AERONET $\mathrm{AE}<1$ are associated with very low $\mathrm{AOD}$ values.

\subsection{SSA studies}

We used single scattering albedo (SSA) data from AERONET level 2.0 inversion products to study whether absorption could explain the differences between MODIS and AERONET AOD values. To avoid measurement uncertainties associated with low AOD values, only measurements
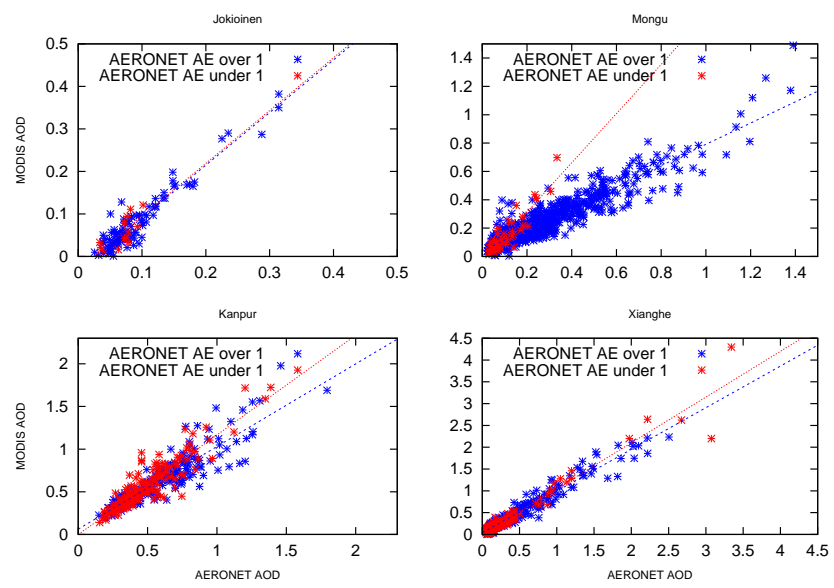

Fig. 2. Correlation of AERONET/PFR and MODIS measurements in Jokioinen, Mongu, Kanpur and Xianghe. Blue points indicate measurements with AERONET AE over 1, and red points measurements with AERONET AE smaller than 1.

with AOD at $550 \mathrm{~nm}$ over 0.3 (both MODIS and AERONET) were considered. The AERONET SSA value was thought to be representative for the MODIS retrieval if the time difference between the measurements was less than $10 \mathrm{~h}$. Figure 3 shows two examples of comparisons of SSA spectra for MODIS a-priori aerosol models with SSA values from the AERONET inversion categorized by MODIS AE. At Torravere, the a-priori SSA spectra in the MODIS algorithm are in agreement with the AERONET data for both size classes. The classification of the coarse aerosol particles coincides with a strong dust plume advected from the Sahara on the 22 March 2007 (based on HYSPLIT backtrajectories (Draxler and Rolph, 2010; Rolph, 2010), thus for these cases MODIS selects the aerosol models correctly. On the other hand, the SSA spectra measured by AERONET in Mexico City are lower than those for the a-priori model, at each wavelength. Similar behavior was also detected at Ispra and Mongu. On the basis of AERONET AE, none of these sites were influenced by coarse particles during these measurements. This can also be seen from the spectral behavior of the AERONET SSA. At Torravere, the averaged SSA of the cases with MODIS AE $<1$ looks like the dust model, and the average of the cases with MODIS AE $>1$ looks like the fine model. At Mexico City, on the other hand, the spectral dependence of the AERONET SSA does not look like either of the MODIS assumed models. However, both cases have the same wavelength dependence, indicating more absorbing fine mode aerosols than assumed in the model. The only difference between the types is that on average the measurements where MODIS detects $\mathrm{AE}<1$ are associated with smaller AERONET SSA values. This raises the question whether the absorption characteristics of the fine mode aerosols could affect the selection of the aerosol model combination in the MODIS aerosol retrieval. However, before we 

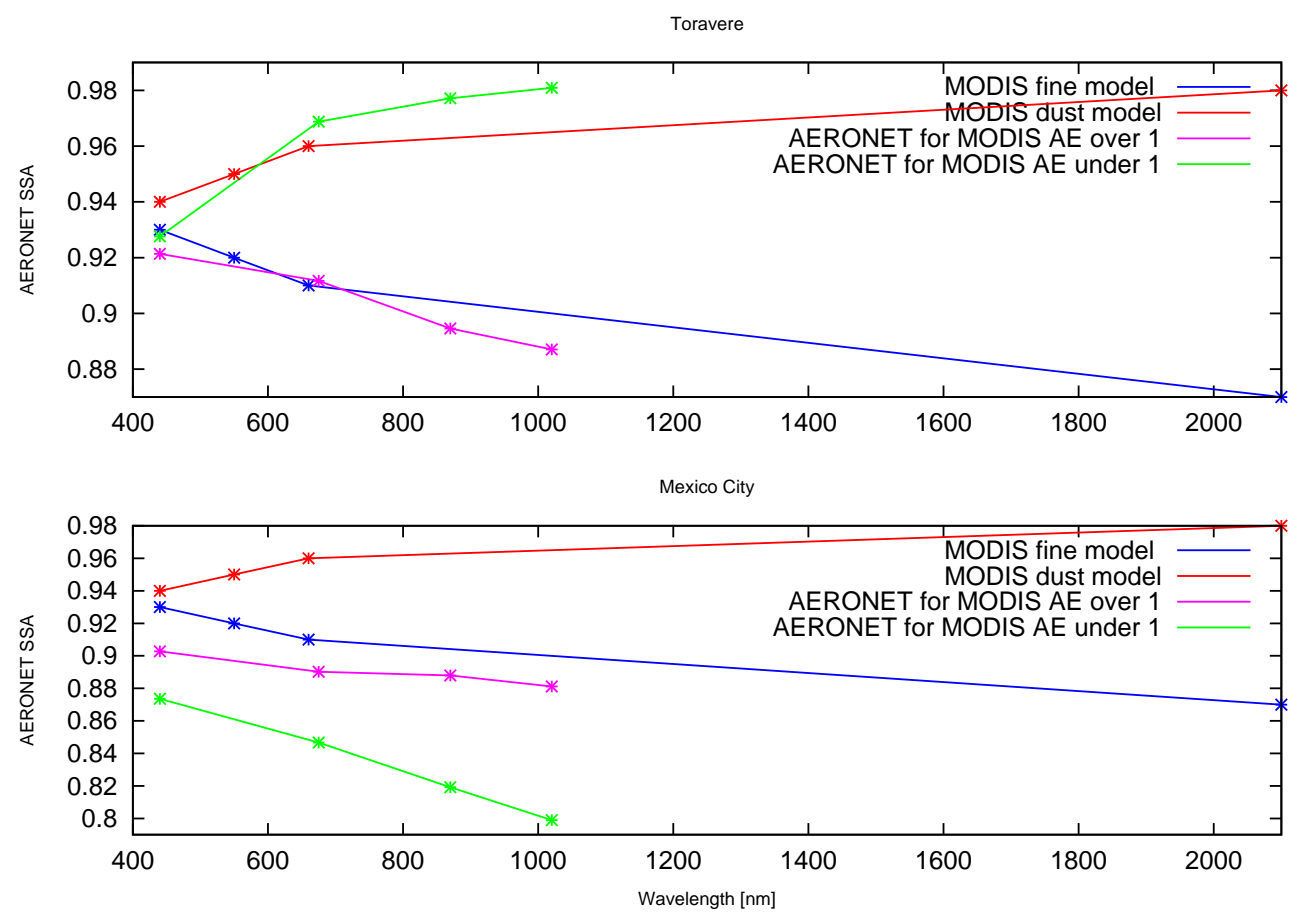

Fig. 3. MODIS aerosol model SSAs compared with AERONET SSA products at two sites: Tõravere and Mexico City. SSA spectra for a-priori dust and fine models (moderately absorbing) used in MODIS retrieval are shown in red and blue, respectively. The magenta line represents the averaged SSA spectrum from AERONET measurements for observations whose MODIS AE is over 1 (fine model). The green color is an average for observations whose MODIS AE is smaller than 1 (dust model). At Tõravere the dust measurements are from a single dust episode (22 March 2007). Only measurements with $\operatorname{AOD}(550 \mathrm{~nm})$ values larger than 0.3 (MODIS and AERONET) are considered.

can answer this question we have to study how the aerosol model combination is affected by surface parameterizations, see below.

\subsection{Surface reflectance studies}

In the next step, we investigated how the C5 surface reflectance estimates influence the retrieval of AE. We used individual pixels and divided the data into two classes based on MODIS AE as before. Then we calculated the monthly mean surface reflectances at $660 \mathrm{~nm}$ from all measurements and normalized the surface reflectance values with these mean values to remove seasonal variations. This was done to remove the effects of natural variation in surface reflectance properties due to seasonal cycle of vegetation. Figure 4 presents the normalized surface reflectances for measurements with MODIS AE over 1, and under 1, as a function of AERONET AE. The surface reflectance data was binned into 0.1 wide AE classes. This example from Mongu is also representative for other sites which had a sufficient number of measurements from both classes (Alta Floresta, Kanpur, Xianghe). At these sites, measurements with MODIS AE over 1 had larger normalized surface reflectance values than the measurements with MODIS AE under 1. This was also seen in the $2.13 \mu \mathrm{m}$ surface reflectance data. Surface reflectance should not depend on the AE, as the AERONET AE data shows in Fig. 4 where the normalized surface reflectance for the MODIS measurements with $\mathrm{AE}>1$ is almost constant as a function of AERONET AE. However, in the MODIS retrieval, larger particles (dust model) are associated with lower surface reflectance values than small particles (fine model). Based on these results, it seems that both aerosol absorption and surface parameterizations could have effects on the aerosol model combination in the MODIS retrieval. In order to separate their effects, we have to study the retrieval algorithm in more detail.

\section{Analysis of the MODIS retrieval algorithm}

To determine why MODIS tends to wrongly identify dust in certain scenes, we need to focus on the details of the MODIS algorithm. Specifically, we try to determine which algorithm assumptions are violated, and why the retrieval behaves as it does.

The MODIS aerosol retrieval assumes that the measured reflectance $\left(\rho^{*}\right)$ at the top of the atmosphere (TOA) is composed of atmospheric "path radiance" $\left(\rho_{a}\left(\theta, \theta_{0}, \phi\right)\right)$ and transmission of surface reflectance through the atmosphere:

$$
\begin{aligned}
& \rho^{*}\left(\theta, \theta_{0}, \phi\right) \\
& =\rho_{a}\left(\theta, \theta_{0}, \phi\right)+F_{d}\left(\theta_{0}\right) T(\theta) \rho^{s}\left(\theta, \theta_{0}, \phi\right) /\left(1-s \rho^{s}\left(\theta, \theta_{0}, \phi\right)\right)
\end{aligned}
$$




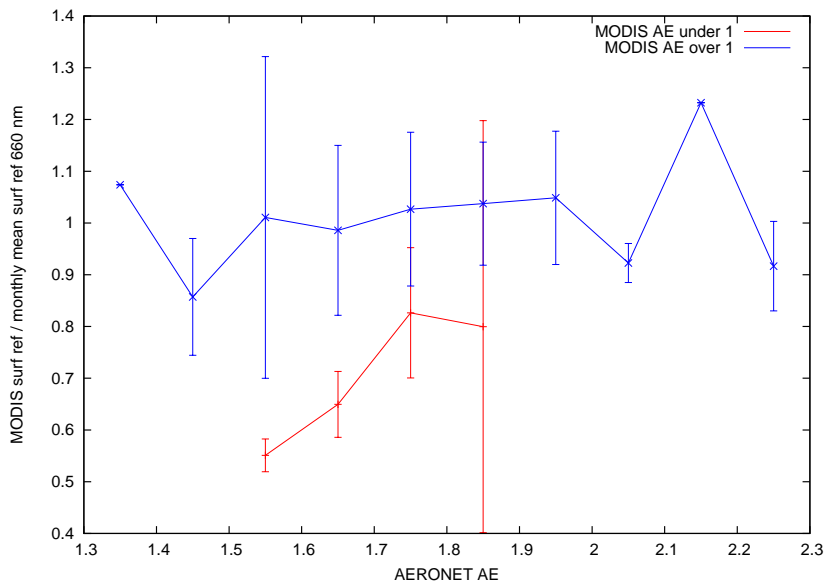

Fig. 4. MODIS surface reflectance at $660 \mathrm{~nm}$, normalized with monthly mean values as a function of AERONET AE. All available measurements from Mongu were used. Measurements with MODIS AE over (blue) or under (red) than 1 are shown separately. Only measurements with AOD $(550 \mathrm{~nm})$ values larger than 0.3 (MODIS and AERONET) are considered. In addition, standard deviations of the surface reflectances inside the bins are shown with bars.

Here $\theta$ is the view zenith angle, $\theta_{0}$ is the solar zenith angle and $\phi$ is the azimuth angle of the scattered radiation from the solar beam. $F_{d}\left(\theta_{0}\right)$ is the normalized downward flux for zero surface reflectance, equivalent to the total downward transmission, $T(\theta)$ is the upward total transmission into the satellite field of view, and $s$ is the atmospheric backscattering ratio (Kaufman et al., 1997).

Since values of $\rho_{a}\left(\theta, \theta_{0}, \phi\right), F_{d}\left(\theta_{0}\right), T(\theta)$, and $s$ are unknown properties of the atmosphere, and the surface reflectance is also unknown, Eq. (1) cannot be solved directly. Instead, the MODIS retrieval algorithm is designed to solve Eq. (1), by referring to the lookup tables (LUT) containing simulated values of $\rho_{a}\left(\theta, \theta_{0}, \phi\right), F_{d}\left(\theta_{0}\right), T(\theta)$, and $s$. Therefore, Eq. (1) can be inverted, solving for the surface reflectance, e.g.,

$\rho^{s}\left(\theta, \theta_{0}, \phi\right)=\frac{\rho_{a}\left(\theta, \theta_{0}, \phi\right)-\rho^{*}\left(\theta, \theta_{0}, \phi\right)}{s\left(\rho_{a}\left(\theta, \theta_{0}, \phi\right)-\rho^{*}\left(\theta, \theta_{0}, \phi\right)\right)-F_{d}\left(\theta_{0}\right) T(\theta)}$

Starting with the $2.13 \mu \mathrm{m}$ wavelength, the MODIS algorithm determines the surface reflectance that solves the equation, repeating for each of seven aerosol loadings (corresponding to AOD at $0.55 \mu \mathrm{m}$ of $0.0,0.25,0.5,1.0,2.0,3.0$, and 5.0 ), and for the fine and dust models, separately. For each loading/model scenario, the calculated surface reflectance at $2.13 \mu \mathrm{m}$ is transferred to $660 \mathrm{~nm}$ and $470 \mathrm{~nm}$ with the following Eqs. (Levy et al., 2007a):

$\rho_{660}^{s}=\rho_{2130}^{s} \cdot$ slope $_{660 / 2130}+$ yint $_{660 / 2130}$

and

$\rho_{470}^{s}=\rho_{660}^{s} \cdot$ slope $_{470 / 660}+$ yint $_{470 / 660}$ where

slope $_{660 / 2130}=$ slope $_{660 / 2130}^{\mathrm{NDVISWIR}}+0.002 \Theta-0.27$,

yint $_{660 / 2130}=-0.00025 \Theta+0.033$

slope $_{470 / 660}=0.49$, and

yint $_{470 / 660}=0.005$

where in turn

$$
\begin{aligned}
& \text { slope }_{660 / 2130}^{\text {NDVISWIR }_{\text {I }}}= \\
& \left\{\begin{aligned}
0.48 & ; \mathrm{NDVI}_{\text {SWIR }}<0.25 \\
0.48+0.2\left(\mathrm{NDVI}_{\mathrm{SWIR}}-0.25\right) & ; 0.25<\mathrm{NDVI}_{\text {SWIR }}<0.75 \\
0.58 & ; \mathrm{NDVI}_{\mathrm{SWIR}}>0.75
\end{aligned}\right.
\end{aligned}
$$

and

$\Theta=\cos ^{-1}\left(-\cos \theta_{0} \cos \theta+\sin \theta_{0} \sin \theta \cos \phi\right)$.

Determined by empirical fitting (Levy et al., 2007a) the slope $660 / 2130$ and $y$-int $660 / 2130$, are coefficients to the linear equation transferring surface reflectance from $2.13 \mu \mathrm{m}$ to $660 \mathrm{~nm}$; likewise similar coefficients transfer surface reflectance from 660 to $470 \mathrm{~nm}$. $\Theta$ is the scattering angle and NDVI $_{S W I R}$ is the Normalized Difference Vegetation Index at IR, defined as

$\mathrm{NDVI}_{\text {SWIR }}=\frac{\rho_{1.24}^{*}-\rho_{2.13}^{*}}{\rho_{1.24}^{*}+\rho_{2.13}^{*}}$.

where $\rho_{1.24}^{*}$ and $\rho_{2.13}^{*}$ are the MODIS-measured reflectances at $1.24 \mu \mathrm{m}$ and $2.13 \mu \mathrm{m}$.

By these equations, the surface reflectance in the two visible channels $(470$ and $660 \mathrm{~nm}$ ) can be estimated from the reflectance at $2.13 \mu \mathrm{m}$. Equation 1 is then applied to estimate TOA reflectance $\left(\rho^{*}\right)$ in the two visible wavelengths. Note that the result is the estimated TOA reflectance in three channels $(470 \mathrm{~nm}, 660 \mathrm{~nm}$ and $2.1 \mu \mathrm{m})$, corresponding to seven aerosol loadings, for the fine and coarse models, separately. These estimated TOA values, can be compared with the observed TOA reflectance. By interpolating between entries of aerosol loading, the algorithm finds the exact loading which satisfies equality between the estimated and observed TOA reflectance at $470 \mathrm{~nm}$.

Now, the algorithm can mix the fine and coarse models. By iterating the model mixing (FMW) through steps of 0.1, while simultaneously recalculating surface reflectance that satisfies the surface reflectance parameterization, the algorithm arrives at different TOA estimates for different mixtures. Equality is required at $470 \mathrm{~nm}$ and $2.1 \mu \mathrm{m}$, however there will be differences between estimated and observed values at $660 \mathrm{~nm}$. The particular loading/mixture that minimizes the $660 \mathrm{~nm}$ difference is considered as the best solution, thus retrieving both the AOD and FMW. Since spectral AOD is consistently represented by the LUT, it is easy to report AOD at 470 and $660 \mathrm{~nm}$, and derive $\mathrm{AE}$ from these values with the Ångström power law. 
Having AE of 0.6, the dust model has a flatter spectral dependence than any of the fine models $(\mathrm{AE}=1.6)$. Thus, for a given loading index (AOD at $550 \mathrm{~nm}$ ), the coarse (dust) model contributes more to the TOA reflectance at $660 \mathrm{~nm}$ than does the fine model. Since the algorithm has to find the best match at $660 \mathrm{~nm}$, this means that for a given value of surface reflectance at $660 \mathrm{~nm}$, the algorithm must either adjust the total aerosol loading or the relative contribution of the coarse model. If the surface target is "brighter" than expected via the surface parameterization, MODIS may observe larger TOA reflectance than modeled by Eq. (1). In this case, MODIS will compensate by picking a dust only aerosol mixture. As a result, MODIS will indicate dust aerosol even when other observations do not indicate dust in the column.

\subsection{MODIS standalone algorithm}

In order to trace the performance of the MODIS retrieval algorithm, we obtained a "standalone" version of the code. By standalone, we mean a version of the C5 process code that includes all the physics and mathematics of the operational aerosol retrieval, without the subroutines related to cloud screening, pixel selection, or any of the other MODIS processing overhead (making HDF files, etc.). For inputs, the standalone code requires only values of the observation geometry (angles, location, month) and measured spectral TOA reflectance. Its outputs include only AOD, AE and FMW, plus values of the $660 \mathrm{~nm}$ matching error. Therefore, the standalone version enables us to study the mechanics of the retrieval, and test how changes in assumptions can affect the retrieved parameters. Specifically, the standalone algorithm allows us to easily modify the surface reflectance parameterization and determine how changes affect retrievals of total $\mathrm{AOD}$ and $\mathrm{AE}$.

\subsection{Evaluation of the surface assumptions}

The surface parameterization of Levy et al. (2007a), given by Eqs. (3-9), includes a dependence on the NDVI $I_{S W I R}$, (Karnieli et al., 2001). This vegetation index is similar to the standard Normalized Difference Vegetation Index (NDVI; red and NIR; Tucker, 1979) except the use of the two longer wavelengths ( 2.13 and $1.24 \mu \mathrm{m}$ ) helps to reduce aerosol contamination. Basically, the surface parameterization assumes that the slope $660 / 2130$ increases as a function of surfacegreenness.

To evaluate the quality of the assumed surface properties in the algorithm we used a MODIS based surface albedo climatology created by Moody et al. (2005). The global climatology contains spatially complete white-sky albedo (bihemispherical reflectance) data from the years 2000-2004. Moody et al. have also made a five-year aggregate of high quality MOD43B3 data which was filled using an interpolation technique (accuracy of 3-8\%; Moody et al., 2008). This aggregate is assumed to be representative of an average year.
In addition, the data set contains surface albedo statistics (average and standard deviation) sorted by ecosystems. These are available at various resolutions of each 16-day time period's snow-free filled albedo maps for each separate year as well as for the five-year climatology. The statistics are available at various resolutions between $0.5 \times 0.5$ and $90 \times 360$ (degrees of latitude $\times$ degrees of longitude). For our comparisons we selected the albedo statistics for the five-year climatology with the $60 \times 120$ resolution. This data provided us averaged albedo values at three wavelengths $(0.66,1.24$ and $2.13 \mu \mathrm{m})$ categorized by ecotypes at 9 different areas. Combined, these 9 areas cover the whole globe. With the 16-day time resolution we get 23 surface albedo values representing the yearly cycle for each ecotype in each of the 9 areas. The overall absolute accuracy of the MODIS surface albedo data is within 0.05 (Liu et al., 2009).

Surface albedo is the ratio of the radiant flux reflected from a unit surface area into the whole hemisphere to the incident radiant flux of hemispherical angular extent (SchaepmanStrub et al., 2006), thus it is not view angle dependent. The reflectance in the MODIS retrieval, however, depends on the solar and viewing geometry. To minimize the discrepancies resulting from the comparison of slightly different quantities we decided to compare ratios instead of absolute values. The selected ratios were the slope $\mathrm{NDVI}_{660 / 2130}$ and NDVI $\mathrm{N}_{S W I R}$. These parameters were selected because the slope $\frac{\mathrm{NDVI}_{660 / 2130}}{\mathrm{~N} \text { IR }}$ is the most important parameter governing the wavelength dependence of the surface reflectance in the MODIS retrieval and it depends on NDVI $_{\text {SWIR }}$ as shown in Eq. 9. The slope $_{660 / 2130}$ also depends on the scattering angle (as can be seen from Eq. 5), however, the effect of the scattering angle

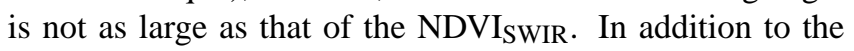
slope $660 / 2130$, the retrieval algorithm uses a ratio of $470 \mathrm{~nm}$ and $660 \mathrm{~nm}$ surface reflectance (slope $470 / 660$ ). However, this second slope does not have a strong effect on the retrieved fine model weighting because Rayleigh optical depth dominates the signal at the shorter wavelengths.

\subsection{Analysis with the standalone algorithm}

We carried out a number of sensitivity studies with the stand-alone version of the MODIS aerosol retrieval algorithm. We modified the surface reflectance parameters (slope $660 / 2130$ and slope $470 / 660$ ) to check how they affect the aerosol model combination (i.e. FMW), AE, and overall AOD. The FMW parameter was most sensitive to the changes in the slope $660 / 2130$ values. Because the slope $660 / 2130$ depends mainly on the slope $\mathrm{NDVI}_{660 / 2130}$, we decided to concentrate on it. Figure 5 shows a typical example from Mongu how the modification of the slope ${ }_{660 / 2130}$ DVIIf affects the aerosol model combination. The black cross is the measured top of the atmosphere (TOA) reflectance at $660 \mathrm{~nm}$ while the magenta square is the result for FMW $=0.5$ from the original retrieval. The red and blue markers are results $(F M W=0.5)$ 


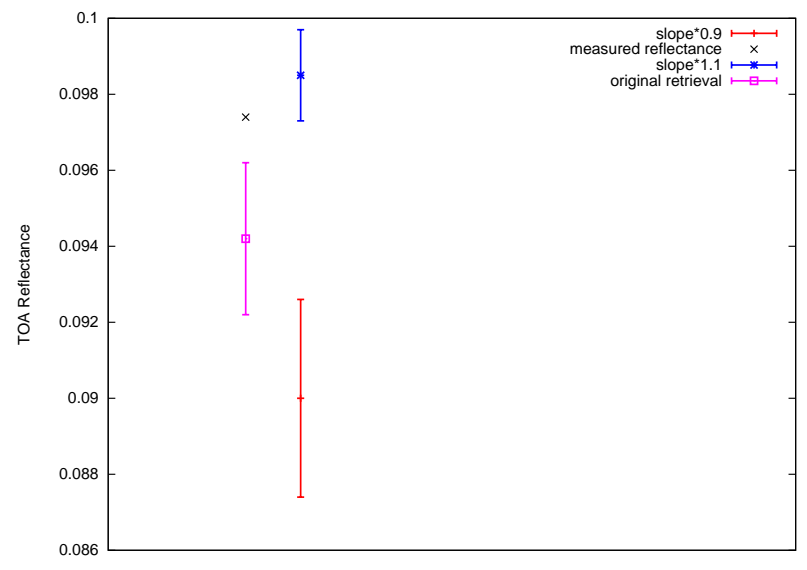

Fig. 5. Sensitivity of the retrieved TOA reflectance at $660 \mathrm{~nm}$ on changes in the slope ${ }_{660 / 2130}^{\mathrm{NDVI}_{\text {SWIR }}}$. The black cross is the observed TOA reflectance at $660 \mathrm{~nm}$ and the magenta square is the result from the original retrieval $(\mathrm{FMW}=0.5)$. The red and the blue markers are results from retrievals $(\mathrm{FMW}=0.5)$ where the slope ${ }_{660 / 2130}^{\mathrm{NDVI}_{\mathrm{SWIR}}}$ is $10 \%$ smaller (0.9) and $10 \%$ larger (1.1), respectively. The errorbars show how much the combination of the dust and fine aerosol models affects the results. The top of the bar indicates unmixed dust model $($ FMW $=0.0)$ while the bottom of the bar is for the unmixed fine model $(\mathrm{FMW}=1.0)$.

from retrievals where the slope ${ }_{660 / 2130}^{\mathrm{NDVI}_{S W I R}}$ has been multiplied by 0.9 and 1.1, respectively. Modification of the slope does not affect the surface reflectance at $2.13 \mu \mathrm{m}$, whereas an increase of $10 \%$ in the slope increases surface reflectance at $660 \mathrm{~nm}$ and $470 \mathrm{~nm}$ by $10 \%$. The errorbars at $660 \mathrm{~nm}$ show how much combining of the fine and dust models affects the results. The top of the bar indicates FMW of zero (dust model) while the bottom of the bar is for FMW of one (fine model). In this case, the original retrieval resulted in the best fit with the unmixed dust model because the measured TOA reflectance at $660 \mathrm{~nm}$ was larger than the calculated one. When the slope ${ }_{660 / 2130}^{\mathrm{NDVI}_{\text {SwIR }}}$ was $10 \%$ larger than the original, the calculated TOA reflectance at $660 \mathrm{~nm}$ became larger and closer to the measured value, thus changing the selected aerosol model from dust to fine. On the other hand, if the slope NDVISWIR $_{660 / 2130}$ was $10 \%$ smaller than the original, the calculated TOA reflectance at $660 \mathrm{~nm}$ moved further away from the measured value without affecting the aerosol type selection.

As illustrated in Figure 5, the combination of aerosol models (and therefore AE) is sensitive to the value of the slope $_{660 / 2130}$, therefore it is extremely important that the slope value represents the surface under investigation very accurately. We made a sensitivity study which showed that in order to have less than $20 \%$ error in the retrieved AE value, the error in the slope $\mathrm{NDVI}_{660 / 2130}$ has to be less than $10 \%$ when AOD is between 0.2 and 0.4. For larger AODs the error in the AE is smaller but for smaller AODs it can be significantly higher. The error of $20 \%$ in $\mathrm{AE}$ means that $\mathrm{AE}$ of
0.6 could vary between 0.48 and 0.72 , and AE of 1.5 could vary between 1.2 and 1.8. This accuracy would still enable the separation between fine and coarse aerosol particles.

To study the quality of the slope-NDVI relationship (slope ${ }_{660 / 2130}^{\mathrm{NDVI}_{\text {SWIR }}}$ in Eq. 9) in the algorithm, we compared it with the MODIS surface albedo climatology. Figure 6 presents the dependence of the slope ${ }_{660 / 2130}^{\mathrm{NDVI}_{\text {SWIR }}}$ on NDVI $\mathrm{NWIR}_{\mathrm{SW}}$ based on global MODIS surface albedo data. The different ecotypes are separated by colors and symbols. In the surface albedo climatology, the globe was divided into 9 areas $(60 \times 120$ degrees each $)$ and averaged surface albedo values for all ecotypes in these areas were calculated. Each ecotype from each of the 9 areas has 23 points representing the yearly cycle of the vegetation. The solid black line in each of these figures shows how the relationship of the parameters is taken into account in the MODIS aerosol retrieval. The albedo data in Figure 6 show that the relationship between NDVISWIR and slope ${ }_{660 / 2130}^{\text {NDVI }_{S W I R}}$ has a large variation between different ecotypes. However, for all ecotypes the slope ${ }_{660 / 2130}^{\text {NDVI }_{S W I R}} \mathrm{de}-$ creases as NDVI $I_{S W I R}$ increases which is opposite to the relationship in the retrieval. This behavior was confirmed with linear regression models which all had negative slope values for each ecotype. In addition, the retrieval assumes smaller slope ${ }_{660 / 2130}^{\text {NDVI }_{\text {SwIR }}}$ values than the surface albedo data shows.

To test how the AE and AOD results are affected if we assume the slope-NDVI relationship to behave more like the albedo data suggest, we applied, as a first try, an inverse relationship that fits the data slightly better (shown in Fig. 6 with dashed lines). As one can see, the inverse relationship fits well to number of ecotypes, e.g. savanna and shrubland. However, it is not able to represent, for example, urban, wetland and needleleaf ecotypes. In an attempt to evaluate the MODIS AE quality we used AERONET AE data. The instruments were in agreement on the particle size if both AEs were either larger than 1.4 or smaller than 0.9 . In other cases the instruments disagreed. The measurements with AEs between 0.9 and 1.4 were left out of the analysis to avoid the difficult comparison of mixed aerosols. In this study, we compared single measurements, whose time difference was less than $10 \mathrm{~min}$. The number of usable measurement (Table 3) varies for the modified retrievals due to the "AE buffer zone" (from 0.9 to 1.4) and the exclusion of retrievals with AOD less than 0.3 or negative surface reflectance at $2.13 \mu \mathrm{m}$. The comparison results are presented in Fig. 7 and in Table 3, which present the AE and AOD agreement parameters for 6 sites. The parameter AE agreement refers to the fraction of AE agreement while mean (gb$\mathrm{M})$ is the averaged AOD difference between the instruments and $R^{2}$ is the correlation coefficient for AOD. Retrievals done with the original slope-NDVI relationship as used in the C5 MODIS aerosol retrieval are called "Original" while the retrievals done with the inverse of that relationship are called "Inverse". Both of these main retrievals have subretrievals where the fine aerosol model was assigned to be 

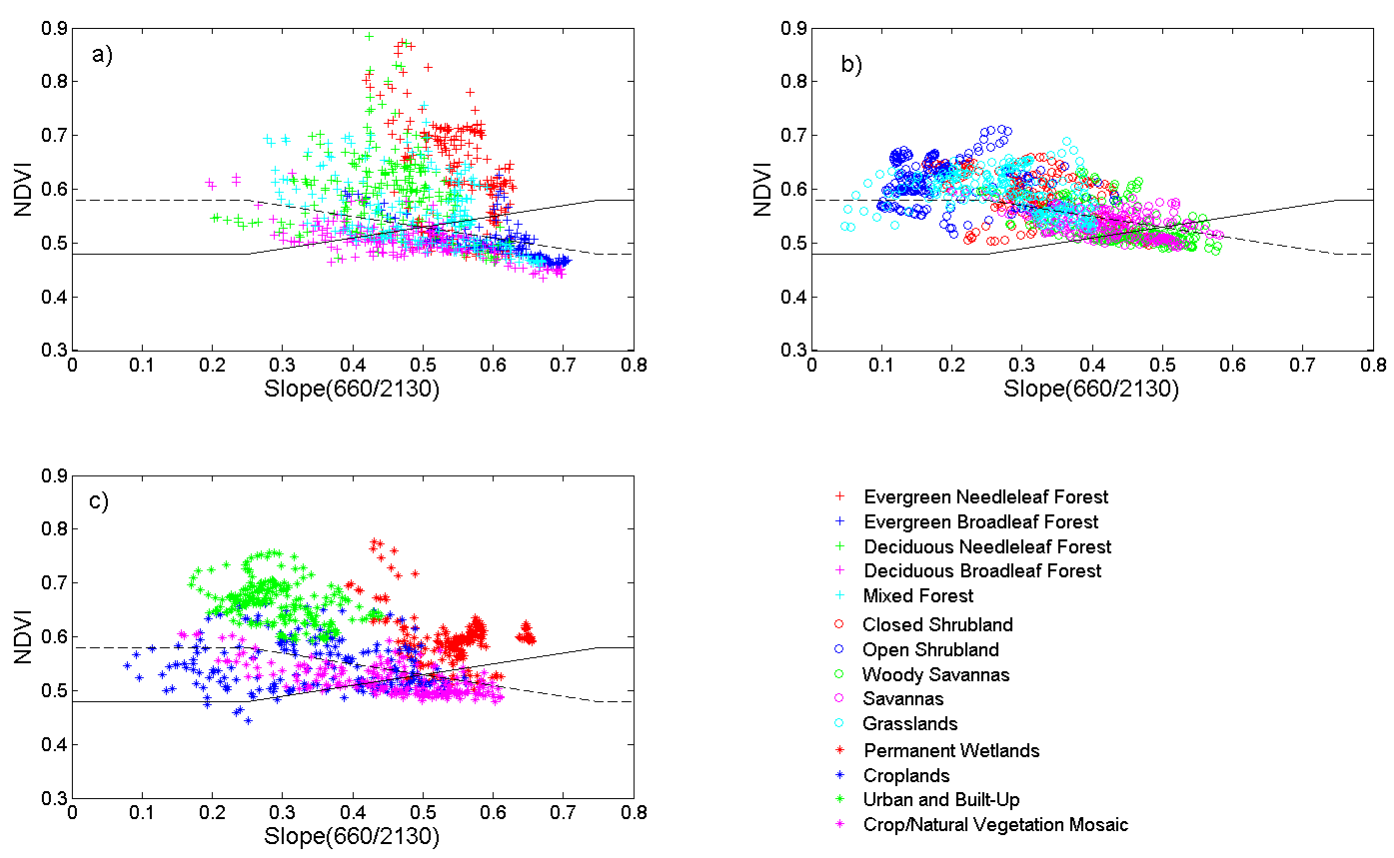

Fig. 6. Dependence of slope ${ }_{660 / 2130}^{N^{2}}$ on NDVI $_{S W I R}$ for different ecotypes based on MODIS surface albedo data. Plot a) presents forest ecotypes (crosses), plot (b) savanna ecotypes (circles) and plot (c) other ecotypes (stars). The solid black line indicates the relationship of the parameters used in the MODIS retrieval (slope ${ }_{660 / 2130}$ ) while the dashed line is the inverse version of it. The inverse relationship appears to be a better fit for a number of ecotypes.

either strongly absorbing (strong, SSA $=0.86$ ) or weakly absorbing (weak, SSA $=0.95$ ) regardless of the fine model originally assigned for the location. Table 3 and Fig. 7 basically show how the selection of the slope-NDVI relationship and fine aerosol model affect the AE and AOD agreement at each site.

Figure 7 and Table 3 show that at all studied sites (Alta Floresta, Kanpur, Mexico City, Mongu, Rome, Xianghe) the modification of the slope-NDVI relationship improved the $\mathrm{AE}$ agreement. For example, in Alta Floresta the original $\mathrm{AE}$ agreement fraction is 0.83 and with the inverse relationship the AE agreement fraction increases to 0.92. When the inverse relationship is combined with the weakly absorbing model, the AE agreement increases to 0.94. Unfortunately, the AOD correspondence at the studied sites does not improve as clearly. The $R^{2}$ values between MODIS and AERONET AOD (R2 in Fig. 7) only improve at Alta Floresta when using the inverse slope-NDVI relationship. In Kanpur and Mexico City the use of the inverse relationship improves the correlation but even better correlation is achieved by merely using a different fine model. However, the averaged AOD difference (mean $(\mathrm{gb}-\mathrm{M}))$ decreases at all sites, except in Mongu and Xianghe. In Mongu and Xianghe all three parameters give mixed results. The best AOD correspondence is achieved with the original slope-NDVI relationship while the best AE agreement is achieved with the inverse relationship. In Alta Floresta, AOD and AE correspondence can be improved at the same time by using the inverse of the slope and weakly absorbing model. The results for Rome are similar as for Alta Floresta, although the $R^{2}$ value for the Inverse(weak) case is not the best possible. In Kanpur and Mexico the two AOD correspondence parameters $\left(R^{2}\right.$ and mean $(\mathrm{gb}-\mathrm{M})$ ) give mixed results. By using the inverted slope-NDVI relationship and strongly absorbing model in Kanpur we get the best values for AE agreement and mean AOD difference, but $R^{2}$ indicates the best AOD correspondence with the original slope-NDVI relationship and absorbing model. Jethva et al. (2010) also concluded that the MODIS retrievals over India could be improved by using a more absorbing fine model and increased surface reflectance in the visible channels. These results show that the absorption of the fine model does not affect the AE agreement, however, it has a significant effect on the AOD correspondence at some sites, like Alta Floresta and Xianghe. The results in Mexico City and Rome are poor in all the cases because they are urban sites with bright surfaces. In addition, Mexico City is an elevated site which also increases the uncertainty in the MODIS retrieval (Levy et al., 2010). Therefore, we studied how much the slope ${ }_{660 / 2130}^{\text {NDVIIR }}$ should be increased at these two sites in order to improve the AE and AOD retrievals. We did the retrievals several times and for each new run we increased the slope by $10 \%$. Then we compared these new retrieval values with AERONET measurements and found 
Table 3. Comparison of the AE and AOD agreement parameters from the original retrieval (Original), and the retrieval with the inverse NDVI-slope relationship (Inverse) at 6 sites. In addition, retrievals where aerosol models were assigned to be either strongly absorbing (strong, $\mathrm{SSA}_{550 \mathrm{~nm}}=0.86$ ) or weakly absorbing (weak, $\mathrm{SSA}_{550 \mathrm{~nm}}=0.95$ ) are presented for both classes. AE agreement refers to the fraction of $\mathrm{AE}$ agreement while mean $(\mathrm{gb}-\mathrm{M})$ is the averaged AOD difference between the instruments (AERONET-MODIS). $R^{2}$ is the correlation coefficient for AOD. These values are also presented in Fig. 6 . The best values for each of the parameters are shown in bold. In addition, the number of measurements used in the comparisons are presented.

\begin{tabular}{|c|c|c|c|c|c|c|}
\hline & Alta Floresta & Kanpur & Mexico City & Mongu & Rome & Xianghe \\
\hline \multicolumn{7}{|l|}{ AE agreement: } \\
\hline Original & 0.825 & 0.903 & 0.136 & 0.804 & 0.319 & 0.787 \\
\hline Original (strong) & 0.869 & 0.910 & 0.117 & 0.804 & 0.304 & 0.804 \\
\hline Original (weak) & 0.865 & 0.917 & 0.115 & 0.803 & 0.309 & 0.792 \\
\hline Inverse & 0.918 & 0.940 & 0.141 & 0.835 & 0.534 & 0.875 \\
\hline Inverse (strong) & 0.930 & 0.945 & 0.167 & 0.844 & 0.472 & 0.872 \\
\hline Inverse (weak) & 0.938 & 0.929 & 0.167 & 0.823 & 0.534 & 0.837 \\
\hline \multicolumn{7}{|l|}{$\operatorname{mean}(\mathrm{gb}-\mathrm{M})$ : } \\
\hline Original & -0.032 & -0.128 & -0.192 & 0.054 & -0.108 & 0.006 \\
\hline Original (strong) & -0.352 & -0.125 & -0.201 & 0.050 & -0.108 & -0.048 \\
\hline Original (weak) & -0.030 & -0.132 & -0.202 & 0.054 & -0.109 & -0.007 \\
\hline Inverse & -0.006 & -0.057 & -0.145 & 0.098 & -0.049 & 0.125 \\
\hline Inverse (strong) & -0.309 & -0.051 & -0.131 & 0.105 & -0.056 & 0.018 \\
\hline Inverse (weak) & 0.000 & -0.057 & -0.133 & 0.104 & -0.049 & 0.122 \\
\hline \multicolumn{7}{|l|}{$R^{2}:$} \\
\hline Original & 0.713 & 0.795 & 0.354 & 0.638 & 0.529 & 0.765 \\
\hline Original (strong) & 0.764 & 0.802 & 0.518 & 0.630 & 0.502 & 0.694 \\
\hline Original (weak) & 0.868 & 0.799 & 0.420 & 0.625 & 0.505 & 0.933 \\
\hline Inverse & 0.748 & 0.788 & 0.466 & 0.517 & 0.505 & 0.715 \\
\hline Inverse (strong) & 0.762 & 0.800 & 0.454 & 0.520 & 0.498 & 0.647 \\
\hline Inverse (weak) & 0.873 & 0.783 & 0.378 & 0.514 & 0.505 & 0.768 \\
\hline \multicolumn{7}{|c|}{ Number of measurements : } \\
\hline Original & 97 & 217 & 81 & 214 & 116 & 47 \\
\hline Original (strong) & 111 & 221 & 77 & 230 & 112 & 56 \\
\hline Original (weak) & 122 & 217 & 78 & 233 & 110 & 53 \\
\hline Inverse & 110 & 184 & 64 & 170 & 73 & 40 \\
\hline Inverse (strong) & 129 & 183 & 66 & 167 & 72 & 47 \\
\hline Inverse (weak) & 129 & 183 & 66 & 164 & 73 & 43 \\
\hline
\end{tabular}

that in Mexico City the slope $\mathrm{NDVISWIR}_{660 / 2130}$ should be as much as 1.6 times larger than the original to introduce significant improvements into the $\mathrm{AE}$ (AE agreement fraction 0.80) and AOD $\left(R^{2}=0.56\right.$ and mean $\left.(\mathrm{gb}-\mathrm{M})=-0.03\right)$ agreements. In Rome, the best AE (AE agreement fraction 0.95) and AOD agreement $\left(R^{2}=0.57\right.$ and mean $\left.(\mathrm{gb}-\mathrm{M})=-0.01\right)$ is achieved with $30 \%$ larger slope $\mathrm{NDVISWIR}_{660 / 2130}$. Similar results were presented by de Almeida et al. (2007) who analyzed the effect of the surface reflectance ratio between the $660 \mathrm{~nm}$ and $2.13 \mu \mathrm{m}$ on AOD retrievals over Mexico City. They found that by increasing the 660/2130 ratio from approximately 0.55 to 0.73 the agreement between the MODIS and sun photometer AOD improved significantly.

\section{Discussion and Conclusions}

We compared Collection 5 MODIS data to PFR and Cimel (AERONET) measurements at eleven locations in Europe, Asia, Africa North America and South America. In northern Europe, the AOD values were quite low $(<0.3)$, especially in northern Finland. AOD values from MODIS and PFR/AERONET in Kanpur, Rome, and Sodankylä agree reasonably well ( $R^{2}$ between 0.78 and 0.80$)$ while AERONET and MODIS measurements in Alta Floresta, GSFC, Ispra, Jokioinen, Mongu, Tõravere, and Xianghe agree very well ( $R^{2}$ over 0.87 ). In Mexico City the $R^{2}$ value was only 0.64 .

The MODIS retrieval algorithm over land often selects the dust aerosol model for locations where dust is unlikely to be found. In addition, there seems to be very little combining of the fine and dust models, meaning that the FMW is typically 1 or 0 . The selection of the dust model reduced the 

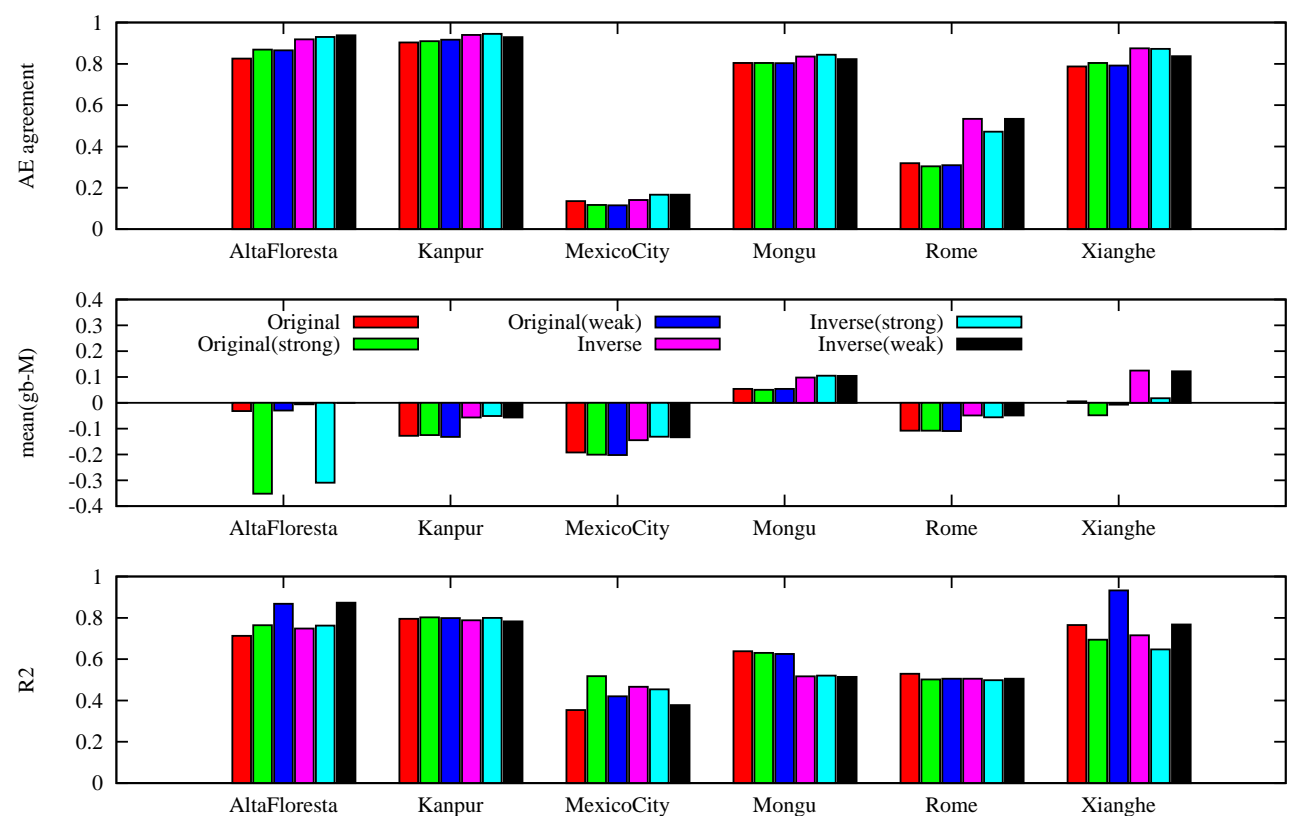

Fig. 7. Comparison of the $\mathrm{AE}$ and $\mathrm{AOD}$ agreement parameters from the original retrieval (Original), and the retrieval with the inverse NDVI-slope relationship (Inverse) at 6 sites. In addition, retrievals where aerosol models were assigned to be either a strongly absorbing (strong, $\mathrm{SSA}_{550 \mathrm{~nm}}=0.86$ ) or weakly absorbing (weak, $\mathrm{SSA}_{550 \mathrm{~nm}}=0.95$ ) are presented for both classes. Colors of the bars refer to these different retrievals. AE agreement (top panel) refers to the fraction of AE agreement while mean(gb-M) (middle panel) is the averaged AOD difference between the instruments and R2 (bottom panel) is the correlation coefficient for AOD. These values are also presented in Table 3 .

correlation between MODIS and ground based AOD at the sites where no significant amount of dust is expected. This happened especially when AOD values were small. According to Levy et al. (2010) MODIS does not provide quantitative information about aerosol size (AE) over land. However, it is an important parameter if one tries to estimate the anthropogenic component of aerosols.

Our findings are in agreement with the recent studies presented by Levy et al. (2010) and Jethva et al. (2010). In contrast to their studies, we also analyzed single MODIS retrievals and therefore were able to study the combining of the fine and dust models in more detail. When employing the spatio-technique of Ichoku et al. (2002), it is harder to see what happens in the combining of the aerosol models due to the averaging of at least 5 measurements. Single measurements, on the other hand, show clearly that the retrieval algorithm usually selects either fine model weighting of 1 or 0 . Because AE depends only on the combination of the models, the AE retrieval fails if the combining fails. Our study suggests that the surface reflectance assumptions, especially the slope $_{660 / 2130} \mathrm{NDVISIR}_{\text {in }}$ in the MODIS algorithm is the major reason for the inaccurate $\mathrm{AE}$ values and the flawed aerosol model combining in the algorithm. Comparison of the surface parameters shows that the slope-NDVI relationship used in the MODIS retrieval algorithm is not supported by the MODIS albedo climatology:
1. the albedo data show that the slope-NDVI relationships depend strongly on ecotypes. The possibility to take this into account in future Collections should be studied further.

2. the slope ${ }_{660 / 2130}^{\mathrm{NDVI} \text { Is }}$ values based on the climatology were larger than the ones in the algorithm.

3. the albedo data also show that the slope $\mathrm{NDVI}_{660 / 2130}^{\mathrm{NVIR}_{\mathrm{I}}}$ decreases as the NDVI increases for all ecotypes which is opposite to the relationship in the algorithm.

4. changing the slope-NDVI relationship in the algorithm to agree better with the albedo data (inverse relationship) increased the correspondence of MODIS and AERONET AE at the studied sites. AOD correlation did not improve as clearly, but the mean difference decreased at all sites, except in Mongu and Xianghe.

5. the uncertainty of the fine model's SSA does not have a significant effect on the AE agreement between MODIS and AERONET, however, it affects the AOD correspondence.

Although, the modification of the slope $\mathrm{N}_{660 / 2130}$ improved $_{\text {ISIR }}$ the AE retrieval at all studied sites and AOD retrieval at some sites, the effect on global scale is not yet known. This will be studied further in the future. 
Acknowledgements. The authors would like to acknowledge the MODIS and AERONET Teams for their effort in making the aerosol data available.

Edited by: S. Kinne

\section{References}

Carlund, T., Landelius, T., and Josefsson, W.: Comparison and uncertainty of aerosol optical depth estimates derived from spectral and broadband measurements, J. Appl. Meteorol., 42, 15981610,2003

de Almeida Castanho, A. D., Prinn, R., Martins, V., Herold, M., Ichoku, C., and Molina, L. T.: Analysis of Visible/SWIR surface reflectance ratios for aerosol retrievals from satellite in Mexico City urban area, Atmos. Chem. Phys., 7, 5467-5477, 2007, http://www.atmos-chem-phys.net/7/5467/2007/.

Draxler, R. R. and Rolph, G. D.: HYSPLIT (HYbrid Single-Particle Lagrangian Integrated Trajectory) Model access via NOAA ARL READY Website (http://ready.arl.noaa.gov/HYSPLIT. php), NOAA Air Resources Laboratory, Silver Spring, MD, 2010.

Drury, E., Jacob, D. J., Wang, J., Spurr, R. J. D., and Chance, K.: Improved algorithm for MODIS satellite retrievals of aerosol optical depths over western North America, J. Geophys. Res., 113, D16204, doi:10.1029/2007JD009573, 2008.

Dubovik, O., Holben, B. N., Eck, T. F., Smirnov, A., Kaufman, Y. J., King, M. D., Tanr, D., and Slutsker, I.: Variability of absorption and optical properties of key aerosol types observed in worldwide locations, J. Atmos., Sci., 59(3), 590-608, 2002.

Eck, T., Holben, B., Reid, J., Dubovik, O., Smirnov, A., O’Neill, N., Slutsker, I., and Kinne, S.: Wavelength dependence of the optical depth of biomass burning, urban, and desert dust aerosols, J. Geophys. Res., 104, 31333-31349, 1999.

Holben, B. N., Eck, T. F., Slutsker, I., Tanré, D., Buis, J. P., Setzer, A., Vermote, E., Reagan, J. A., Kaufman, Y. J., Nakajima, T., Lavenu, F., Jankowiak, I., and Smirnov, A.: AERONET - A federated instrument network and data archive for aerosol characterization, Rein. Sens. Environ., 66, 1-16, 1998.

Ichoku, C., Chu, D. A., Mattoo, S., Kaufman, Y. J., Remer, L. A., Tanré, D., Slutsker, I., and Holben, B. N.: A spatio-temporal approach for global validation and analysis of MODIS aerosol products, Geophys. Res. Lett., 29(12), 8006, doi:10.1029/2001GL013206, 2002.

Jethva, H., Satheesh, S. K., and Srinivasan, J.: Assessment of second-generation MODIS aerosol retrieval (Collection 005) at Kanpur, India, Geophys. Res. Lett., 34, L19802, doi:10.1029/2007GL029647, 2007.

Jethva, H., Satheesh, S. K., Srinivasan, J., and Levy, R. C.: Improved retrieval of aerosol size-resolved properties from Moderate Resolution Imaging Spectroradiometer over India: Role of Aerosol Model and Surface Reflectance, J. Geophys. Res., 115, D18213, doi:10.1029/2009JD013218, 2010.

Kahn, R. A., Banerjee, P., and McDonald, D.: Sensitivity of multiangle imaging to natural mixtures of aerosols over ocean, J. Geophys. Res., 106, 18219-18238, 2001.

Kahn R. A., Nelson, D. L., Garay, M. J., Levy, R. C., Bull, M. A., Diner, D. J., Martonchik, J. V., Paradise, S. R., Hansen E. G., and Remer L. A.: MISR Aerosol Product Attributes and Statistical
Comparisons With MODIS, IEEE Trans. On Geosc. and Remote Sensing, 47, 4095-4114, 2009.

Karnieli, A., Kaufman, Y. J., Remer, L. A., and Ward, A.: AFRI Aerosol free vegetation index, Remote Sens. Environ., 77, 1021, 2001.

Kaskaoutis, D. G., Kosmopoulos, P., Kambezidis, H. D., and Nastos P. T.: Aerosol climatology and discrimination of different types over Athens, Greece, based on MODIS data. Atmos. Env., 41, 7315-7329, 2007.

Kaufman, Y. J., Wald, A. E., Remer, L. A., Gao, B. C., Li, R. R., and Flynn, L.: The MODIS 2.1 m Channel - Correlation with Visible Reflectance for use in Remote Sensing of Aerosol, IEEE Transactions on Geoscience and Remote Sensing, 35, 1286-1298, 1997.

Kim, S.-W., Yoon, S.-C., Dutton, E. G., Kim, J., Wehrli, C., and Holben, B. N.: Global Surface-Based Sun Photometer Network for Long-Term Observations of Column Aerosol Optical Properties: Intercomparison of Aerosol Optical Depth, Aerosol Science and Technology., 42(1), 1-9, 2008.

Levy, R. C., Remer, L. A., Mattoo, S., Vermote, E. F., and Kaufman, Y. J.: Second-generation operational algorithm: Retrieval of aerosol properties over land from inversion of Moderate Resolution Imaging Spectroradiometer spectral reflectance, J. Geophys. Res., 112, D13211, doi:10.1029/2006JD007811, 2007a.

Levy, R. C., Remer, L. A., and Dubovik, O.: Global aerosol optical properties and application to Moderate Resolution Imaging Spectroradiometer aerosol retrieval over land, J. Geophys. Res., 112, D13210, doi:10.1029/2006JD007815, 2007 b.

Levy, R. C., Remer, L. A., Kleidman, R. G., Mattoo, S., Ichoku, C., Kahn, R., and Eck, T. F.: Global evaluation of the Collection 5 MODIS dark-target aerosol products over land, Atmos. Chem. Phys., 10, 10399-10420, doi:10.5194/acp-10-10399-2010, 2010.

Liu, J., Schaaf, C., Strahler, A., Jiao, Z., Shuai, Y., Zhang, Q., Roman, M., Augustine, J. A., and Dutton, E. G.: Validation of Moderate Resolution Imaging Spectroradiometer (MODIS) albedo retrieval algorithm: Dependence of albedo on solar zenith angle, J. Geophys. Res., 114, D01106, doi:10.1029/2008JD009969, 2009.

Liu, L. and Mishchenko, M. I.: Toward unified satellite climatology of aerosol properties: Direct comparisons of advanced level 2 aerosol products, J. Quant. Spectrosc. Radiat. Transfer, 109, 2376-2385, 2008.

Mi, W., Li, Z., Xia, X., Holben, B., Levy, R., Zhao, F., Chen, H., and Cribb, M.: Evaluation of the Moderate Resolution Imaging Spectroradiometer aerosol products at two Aerosol Robotic Network stations in China, J. Geophys. Res., 112, D22S08, doi:10.1029/2007JD008474, 2007.

Mishchenko, M. I., Liu, L., Travis, L. D., Cairns, B., and Lacis A. A.: Toward unified satellite climatology of aerosol properties: 3. MODIS versus MISR versus AERONET, J. Quant. Spectrosc. Radiat. Transfer, 111, 540-552, 2010.

Mishchenko, M. I., Geogdzhayev, I. V., Liu, L., Lacis, A. A., Cairns, B., and Travis, L. D.: Toward unified satellite climatology of aerosol properties: What do fully compatible MODIS and MISR aerosol pixels tell us? J. Quant. Spectrosc. Radiat. Transfer, 110, 402-408, 2009.

Mishchenko, M. I., Geogdzhayev, I. V., Cairns, B., Carlson, B. E., Chowdhary, J., Lacis, A. A., Liu, L., Rossow, W. B., and Travis, L. D.: Past, present, and future of global aerosol cli- 
matologies derived from satellite observations: A perspective, J. Quant. Spectrosc. Radiat. Transfer, 106, 325-347, 2007.

Misra, A., Jayaraman, A., and Ganguly, D.: Validation of MODIS derived aerosol optical depth over Western India, J. Geophys. Res., 113, D04203, doi:10.1029/2007JD009075, 2008.

Moody, E. G., King, M. D., Schaaf, C. B., and Platnick, S.: MODIS-Derived Spatially Complete Surface Albedo Products: Spatial and Temporal Pixel Distribution and Zonal Averages, J. Appl. Meteorol. Clim., 47, 2879-2894, 2008.

Moody, E. G., King, M. D., Platnick, S., Schaaf, C. B., and Gao, F.: Spatially complete global spectral surface albedos: Value-added datasets derived from Terra MODIS land products, IEEE Trans. Geosci. Remote Sens., 43, 144-158, 2005.

Oo, M. M., Jerg, M., Hernandez, E., Picon, A., Gross, B. M., Moshary, F., Ahmed, S. A.: Improved MODIS Aerosol Retrieval Using Modified VIS/SWIR Surface Albedo Ratio Over Urban Scenes, IEEE T. Geosci. Remote, 48, 3, 983-1000, 2010.

Papadimas, C. D., Hatzianastassiou, N., Mihalopoulos, N., Kanakidou, M., Katsoulis, B. D., and Vardavas, I.: Assessment of the MODIS Collections C005 and C004 aerosol optical depth products over the Mediterranean basin, Atmos. Chem. Phys., 9, 2987-2999, doi:10.5194/acp-9-2987-2009, 2009.

Remer, L. A., Kleidman, R. G., Levy, R. C., Kaufman Y. J., Tanré D., Mattoo, S., Martins, J. V., Ichoku, C., Koren, I., Yu, H., and Holben B. N.: Global aerosol climatology from the MODIS satellite sensors, J. Geophys. Res., 113, D14S07, doi:10.1029/2007JD009661, 2008.
Rolph, G. D.: Real-time Environmental Applications and Display sYstem (READY) Website (http://ready.arl.noaa.gov), NOAA Air Resources Laboratory, Silver Spring, MD, 2010.

Salomonson, V. V., Barnes, W. L., Maymon, P. W., Montgomery, H. E., and Ostrow, H.: MODIS, advanced facility instrument for studies of the Earth as a system, IEEE T. Geosci. Remote Sens., 27, 145-153, 1989.

Schaepman-Strub, G., Schaepman, M. E., Painter, T. H., Dangel, S., and Martonchik, J. V.: Reflectance quantities in optical remote sensing - definitions and case studies, Remote. Sens. Environ., 103, 27-42, 2006.

Schuster, G. L., Dubovik, O., and Holben, B. N.: Angstrom exponent and bimodal aerosol size distributions, J. Geophys. Res., 111, D07207, doi:10.1029/2005JD006328, 2006.

Smirnov, A., Holben, B. N., Eck, T. F., Dubovik, O., and Slutsker, I.: Cloud-Screening and Quality Control Algorithms for AERONET Database, Remote. Sens. Environ. 73, 337-349, 2000 .

Tucker, C. J.: Red and photographic infrared linear combinations for monitoring vegetation, Remote Sens. Environ., 8, 127-150, 1979.

Wehrli, C.: Calibrations of Filter Radiometers for Determination of Atmospheric Optical Depth, Metrologia 37, 419-422, 2000. 